\title{
Organizational features in leaves for application in shading systems for building envelopes
}

\author{
L. Badarnah \& U. Knaack \\ Delft University of Technology, The Netherlands
}

\begin{abstract}
Main principles and methods for sunlight tracking in leaves are presented for possible application in shading systems. Plants have developed unique mechanisms for specific climates and locations, where they can determine the amount of exposure for efficient performance. Physiology and geometry are the most significant factors influencing light interception in plants, where leaf distribution, orientation and dynamics influence the exposure to sun radiation.

The possibility of developing a shading system for building envelopes, based on the unique shape and structure of plant leaves, which provide them the desired flexibilities induced by sunlight, is discussed and a summary of the main principles is presented. The shade elements have to be more flexible in all directions, where altitude and azimuth angles of the sun have to be considered. An efficient design of shading system for an envelope is achieved when it is adapted to the sun radiation path of each day.
\end{abstract}

Keywords: inclination, orientation, distribution, flexibility, shading, leaves.

\section{Introduction}

The sun is the basic source of energy for most living creatures. Through millions of years of evolution, creatures have adapted to optimized performances. Hence, living organisms can regulate, in most cases, and control the amount of gained radiation to their system. Plants are organisms that have a significant relation to sun radiation. The relation between light and leaves has been investigated and reported by numerous biologists [1-4]. Morphological and physiological factors influence light interception in plants [5], where it affects photosynthesis and rate of plant productivity [6]. The photosynthesis process has a direct relation to sun 
radiation, where plant growth is affected by a significant environmental factor which is light [7].

The building envelope is considered as one of our external protecting layers. In terms of solar radiation, demands and requirements on the envelope are dramatically increased throughout winter and summer [8]. Controlling the permeated amount of light is done through the envelope, where shading devices are attached to the surface, externally or internally. These shading devices include solid shadings, canvas awning, roller shades, blinds and louvers. This paper focuses on external shading elements, due to their effectiveness in blocking solar radiation before reaching the indoor environment [9].

A shading system with an efficient sun-radiation control could reduce peak heat-loads in buildings, reduce cooling requirements and improve natural lighting and external visual contact. Energy-efficient building design is influenced significantly by the proposed shading device. Shading systems have to consider the orientation and location of the specific building facade.

So far, advantages from plants are not yet well utilized for designing shading systems for building envelops. In this paper techniques abstracted from plants that respond to sunlight are discussed for possible application in shading systems for building envelops, with the property of adapting to changing conditions of sun-radiation.

\section{Plants: leaves responding to sunlight}

A leaf is a flat and thin structure, its main purpose is to expose the cells containing the chloroplast to sunlight for photosynthesis. From this information we come to the idea that the plant is very much influenced by sunlight. It is possible to get a better idea of the main principles that plants use for exposing to sunlight by observing and studying their special organizational features. In this context, leaf distribution, orientation and dynamics play a significant role in influencing the exposure to sun radiation.

\subsection{Distribution/position}

The geometric structure has a great impact on plants in nature [10]. Morphological and physiological factors influence light interception in plants [5]. Thus, these affect photosynthesis and rate of plant productivity [6]. Leaf special arrangement and leaf density are factors that affect distribution in plants for efficiency. They affect and reduce the ability of solar tracking at the plant canopy [3].

- Leaf special arrangement:

Form and proportion are two of the main factors for efficiency [11]. Some plants have special arrangements that could be described mathematically, e.g. Fibonacci series found in sunflowers and pinecones; these arrangements are adopted for compact and dense packing of leafs.

Fibonacci series could be applied in two or three dimensions. In fig. 1, a Fibonacci pattern is applied, where leaves grow in size but they don't change 
their shape. In the illustration a two dimensional and horizontal growth is maximized by adopting the Fibonacci series and it packs a maximum amount of elements in the minimum area.
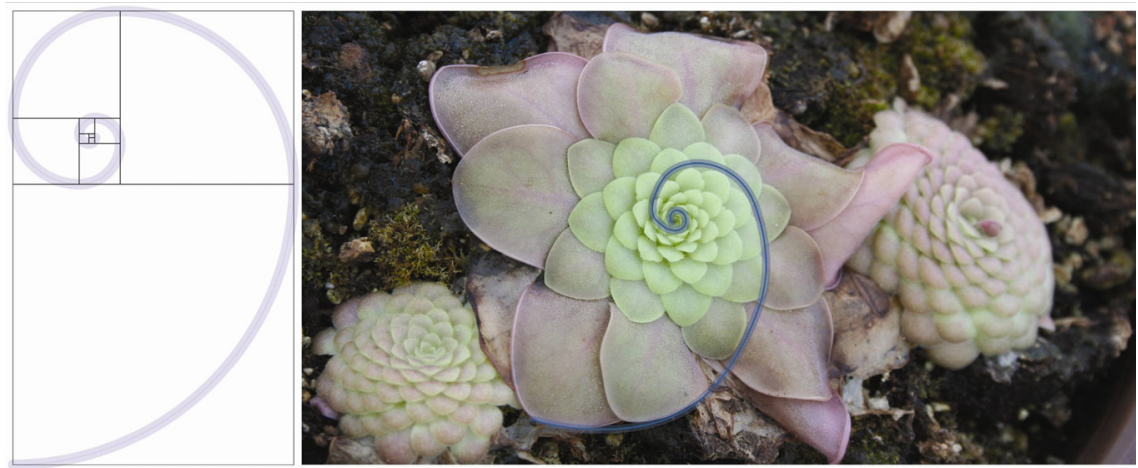

Figure 1: Horizontal growth, Fibonacci series for compact horizontal packing.

- Leaf density and expansion:

It had been reported that leaf distribution for photosynthesis efficiency is achieved by: a monolayer with high density or multi-layer with loose distribution [12]. The leaf density of plants, influences the plants' projected area, which leads to the relation between the plants' projected area and sunlight interception capability [13].

It had been reported that in shaded environments, species tend to have taller stems while understory species tend to expand horizontally with less height than canopy species [1]. By expanding horizontally they maximize their leaf area for maximum exposure of diffused light.

\subsection{Orientation/inclination}

The regulation of leaf orientation is a complex response that is dependent on successful integration of multiple photoreceptors, hormonal signals and gating by the circadian clock [14]. Three categories of leaf reorientation [15]:

1- Nyctinastic (sleep movements)

2- Seisonastic (movements in response to shaking)

3- Heliotropic (leaf movements tracking the sun)

This article focuses on Heliotropic response, because it is affected by sun radiation dynamics. In plants, sun tracking is achieved in two ways: move leaves perpendicular to the direct sun rays, which are called diaheliotropic leaves, and move leaves parallel to direct sun rays, are called paraheliotropic [3].

Heat load, leaf temperature and transpiration rate are reduced at paraheliotropic movements [16]. Diaheliotropic movements, fig. 2, allow a high solar irradiation and result in maximal rates of photosynthesis throughout the day [17]. 
Plants tend to vary their inclinations in order to regulate light interception according to different climates. At hot and dry climates plants leaves face east, by that they maximize light interception in the early morning and late afternoon while keeping a minimum interception at noon [2]. Uniformly distributed leaves in all azimuthally directions with an inclination of $70^{\circ}$, has a relative well performance in all seasons at all hours of the day, where high leaf angles reduce noon canopy heat-loads [18]. Leaves becoming more vertical, is a method for
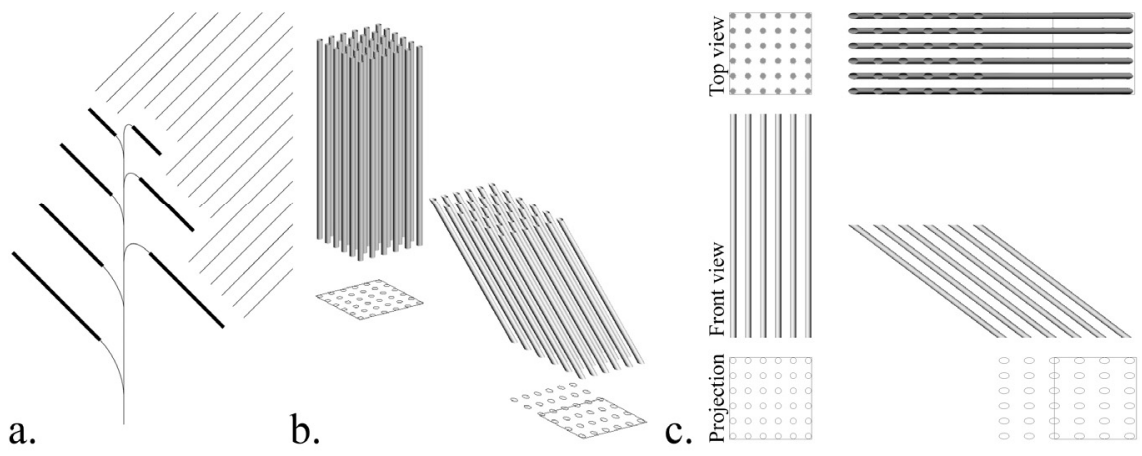

Figure 2: The angle of incidence determines energy density. (a) Leaves normal to sun radiation for maximum energy gain. (b) The effect of different inclination on the projection. (c) Top, front and projection view.
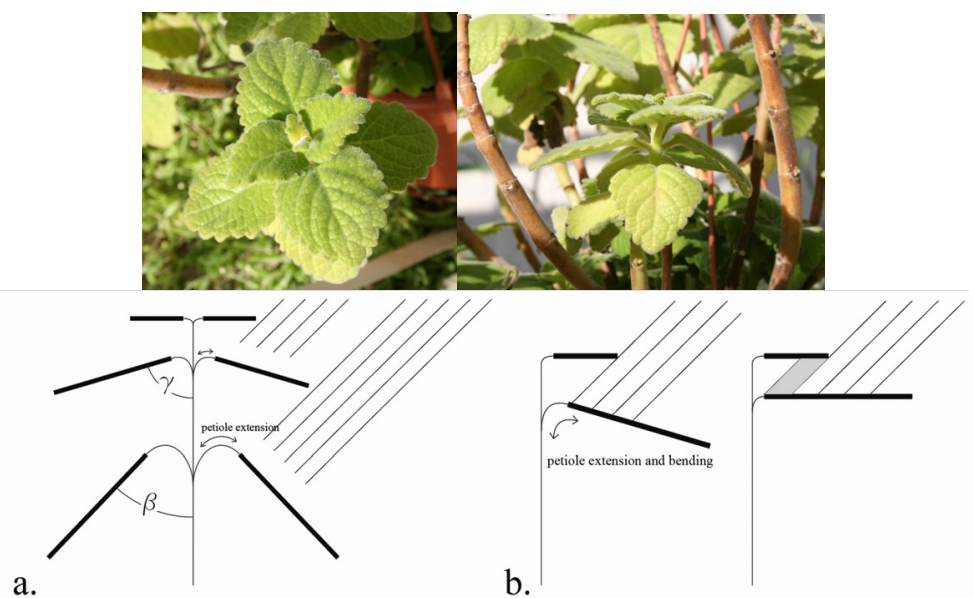

Figure 3: $\quad$ Lower layers of leaves bend for maximum light perception. (a) Lower leaves get bigger with smaller inclination $(\beta<\gamma)$. Alternation of 90 degrees is adopted in this plant for more space between the layers in order to catch more sunlight. (b) The effect of the inclination, preventing self shading. 
protection from over exposure of sunlight $[18,19]$. When facing north (southern the equator, e.g. Argentina) a gradual warming of leaves is occurred during the morning and a maximum light gaining at winter noon's [2].

\subsection{Dynamics}

Plasticity in response to sunlight is one of the dominant aspects of plant architecture [7]. This plasticity is recognized when leaflets shift from a vertical position to a horizontal position. In this process plants increase their internode and petiole length, and leaves increase their area while reducing mass per unit area.
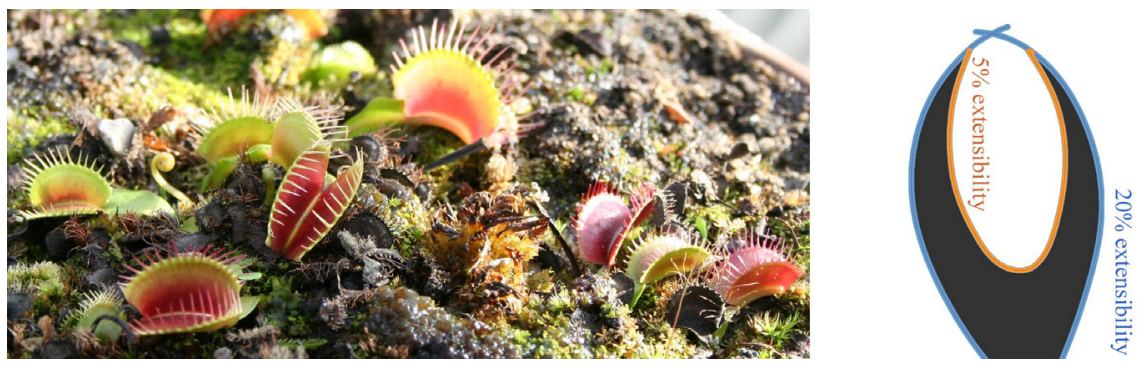

Figure 4: Venus flytrap. At right, a cross section showing different extensibilities for the inner and outer surfaces.

When new leaves are developing, causing self-shading, the lower leaves, which are getting shaded by the new ones, rotate in the horizontal plane to minimize the shade caused by the new leaves [7]. Reorientations are caused by inclination of leaves and by differential growth in the expanding leaves, especially at the petiole, resulting in leaf curvature [14].

Dynamics in plants are generated due to their nastic structure [22]. The following examples will illustrate different functions of nastic structures:

1- Rapid bending: The Venus flytrap has one of the fastest nastic movements in plants [23], it consists of two wings that are able to close and trap insects in between (for nitrogen supply). Sensory hairs are attached to the edges of the wings, which give signals for trapping when touched. The closure is achieved thanks to property differences at the exterior and interior surface of the wing, fig. 4. The inner surface is able to extend $5 \%$, while the outer surface is $20 \%$.

2- Folding/unfolding: many plants have this property for preventing transpiration water loss [22]. The folding or rolling is either downwards or upwards, and can also be along the main axis. The position of uncoated cell clusters (top or bottom) determines the folding direction. When they are dehydrated and contracted, the surface will get smaller which results in folding. This process is reversible.

3- Orienting horizontally or vertically: this property is adapted basically to track sun radiation. The centralization of vascular bundles in the leaf stalk allows 
the leaf to bend. A certain chemical reaction results in a simple and reversible buckling that causes the leaf to drop vertically [24].

4- Volume flexibility: this property is related to the entire body of plants shrinking or extending. Paturi [25] mentioned for the first time the submerging of a cactus below the desert ground at the dry season by shrinking and reducing shoot length. Other desert plants have the property of shrinking their shoot while having the same surface area; in this case the surface is transformed from a concave to a convex shape. This unique change provides a self-shading situation for the plants at extensive exposure to sunradiation.

\section{Summary of techniques used in light-responsive plants}

Table 1: $\quad$ Summary of main organizational features in leaves for minimum and maximum light exposure.

\begin{tabular}{|c|c|c|c|}
\hline & $\begin{array}{l}\text { Distribution/ } \\
\text { position }\end{array}$ & Orientation/inclination & Dynamics \\
\hline 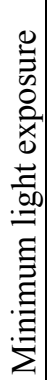 & $\begin{array}{l}\text { - dense distribution at } \\
\text { multi-layer } \\
\text { - loose distribution at } \\
\text { mono-layer } \\
\text { - minimum projected } \\
\text { area }\end{array}$ & $\begin{array}{l}\text { - parallel to sun-rays } \\
\text { (Paraheliotropic) } \\
\text { - facing east for minimum } \\
\text { exposure at noon } \\
\text { - high leaf angles (more } \\
\text { vertical) for minimum } \\
\text { exposure at noon } \\
\text { - facing south/north for gradual } \\
\text { exposure during morning } \\
\text { - leaflet folding } \\
\text { - low leaf angles }\end{array}$ & $\begin{array}{l}\text { - parallel to sun-rays } \\
\text { (Paraheliotropic) } \\
\text { - folding / rolling } \\
\text { - bending } \\
\text { - buckling } \\
\text { - vascular bundles } \\
\text { - concave surface shape }\end{array}$ \\
\hline 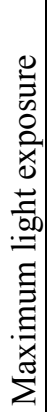 & $\begin{array}{l}\text { - loose distribution at } \\
\text { multi-layer } \\
\text { - dense distribution at } \\
\text { mono-layer } \\
\text { - maximum projected } \\
\text { area } \\
\text { - Fibonacci series for } \\
\text { compact pattern } \\
\text { packing } \\
\text { - extending stem } \\
\text { - horizontal } \\
\text { expansion }\end{array}$ & $\begin{array}{l}\text { - perpendicular to sun-rays } \\
\text { (Diaheliotropic) } \\
\text { - facing east for maximum } \\
\text { exposure at morning and } \\
\text { afternoon } \\
\text { - facing south/north for } \\
\text { maximum exposure at winter } \\
\text { noon's }\end{array}$ & $\begin{array}{l}\text { - increasing internode and } \\
\text { petiole length } \\
\text { - increasing leaf area combined } \\
\text { with reducing mass per unit } \\
\text { - plasticity, nastic structure } \\
\text { - different flexibilities of the } \\
\text { sides of a blade } \\
\text { - special surface properties- } \\
\text { uncoated cell clusters (for } \\
\text { flexibility) } \\
\text { - convex surface shape }\end{array}$ \\
\hline
\end{tabular}

\section{Current shading technologies for building envelopes}

Shading systems are attached to buildings, as mentioned earlier, in order to control the amount of radiation on the glass for reducing heat loads, while providing a visual contact with the exterior environment. Current shading technologies deal, basically, with extensions either vertically or horizontally. Or 
by adding an extra cladding to protect against radiation from glazed openings, while leaving some amount of light to penetrate inside.

When having Louvre panels either vertical or horizontal, fig. 5, the sun radiation changes are controlled by flipping the louvers to different angles. However, these louvers are not adapted, three-dimensionally, to track the exact sun radiation throughout the day. They tend to have the same angle of inclination when flipped, fig. 6 . Venetian blinds, which consist of adjustable louvers, can be divided into separate parts, for controlling and adjusting them in different inclinations. This will control the sun radiation to get deeper in the room or reflecting it [8]. But still, this division has a limited adjustability, when the louvers are flipped they still have the same angle of inclination.

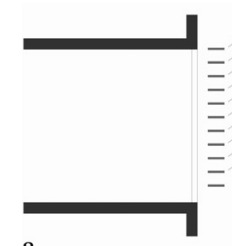

a.

Figure 5: $\quad$ Simplified version of current shade devices. (a \& b) horizontal shade devices for high angles of radiation. (c) Vertical shade devices for low angles of radiation (morning and evening).

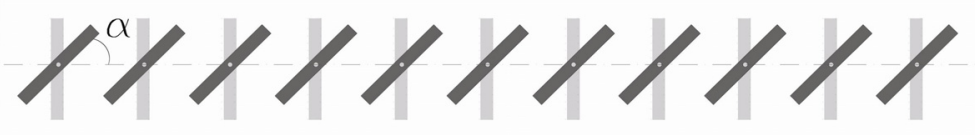

Figure 6: All shade blades have the same angle of inclination $(\alpha)$ when flipped. Light gray indicates the old position and dark gray the new position.

Other approaches than attaching a two dimensional system to building envelopes are available, such as the shade elements for Singapore Lyceum Theatre. The attention of the architects (DP Architecs) was, that the enveloping facade system changes pattern to suit the orientation, providing solar shading and controlling the internal environment of the pavilions [26]. The structural geometry was inspired from nature, like sunflowers, fish scales etc. However, each shade device is not adjusting itself throughout the day or seasons according to sun-ray angles. The study of the location (latitude) and climate conditions is the main factor affecting an effective shading system design [27].

Current technologies for shading devices used in buildings deal with limited adjustability of these devices, where they are designed for the extreme situations of solar radiation and not for the whole exposure of solar radiation. Furthermore, they are not adapted to changing conditions of solar radiation throughout the day, if it is cloudy or sunny. 


\section{Principles abstraction from plants and their possible application for building envelopes}

From summarizing the techniques used in plants for reacting to sun radiation, three main categories are recognized for maximum and minimum light exposure, as shown in table 1. Principles from the different categories influence the plant to track the sun effectively. Furthermore, in order to achieve dynamics, the structural geometry is very significant. Geometry is a major aspect for determining the distribution, inclination and dynamics.

For maximum exposure, leaves tend to have a clear organization and distribution with an adaptive inclination and relatively high plasticity in the plant's body. At minimum exposure, plants are less dynamic and reorient when having high exposure, e.g. at noon, also they tend to have low leaf inclinations, preventing conditions such as normal to rays.

In order to apply these principles in building envelope, a transformation process has to be carried out. This transformation is important where it transforms natural principles and methods into technical solutions for building envelopes [28]. In this case, the transformation should result in a shading system for building envelopes.

A building envelope differs from a plant by its layout and shape, and has additional demands for users comfort. In this complex process, plant's mechanisms and building envelope's demands need to be integrated.

Based on the unique shape and structure of plant leaves, which provide them the desired flexibilities induced by sunlight, it is possible to develop a system providing shading and also energy generating, where the side facing radiation has integrated cells for gaining energy and by that provides shade for underneath.

\section{Conclusions}

Organizational features in plants offer varied solutions for tracking sun radiation, either paraheliotropic or diaheliotropic. They have developed unique mechanics for specific climates and locations, where plants can determine the amount of exposure for the efficient performance. Physiology and geometry are the most significant factors influencing light interception in plants.

Current shading systems have a limited adjustability for sun radiation. Shade elements flipping around an axis do not cover the optimum radiation (as mentioned earlier). The shade elements have to be more flexible in all directions where altitude and azimuth angles of sun have to be taken into consideration, fig. 7. An efficient design of shading system for an envelope is achieved when it is adapted to the sun radiation path of each day, fig. 7. Abstracting the main principles from plants and transforming them into technical solutions for buildings, seems to be a promising development. Further investigation on the means by which plants adopt for dynamics is needed for transformation into shading systems for buildings. 


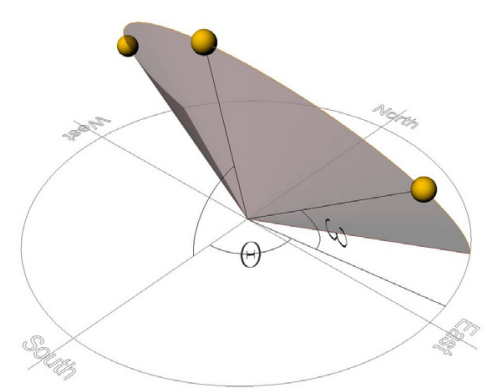

Figure 7: Sun position. Altitude and azimuth angles determine the position of sun. The altitude angle $(\omega)$ is the angle of sun above the horizon and the azimuth $(\theta)$ is the angle of sun's projection on the ground plane relative to south. The hatched surface presents the sun radiation path throughout a specific day.

\section{References}

[1] Poorter, L. \& Werger, M.J.A., Light environment, sapling architecture, and leaf display in six rain forest tree species. American Journal of Botany, 86(10), pp. 1464-1473, 1999.

[2] Ezcurra, E., Montana, C. \& Arizaga, S., Architecture, light interception, and distribution of Larrea species in the Monte Desert. Argentina. Ecology, 72(1), pp. 23-34, 1991.

[3] Ehleringer, J.R. \& Forseth, I., Solar Tracking by Plants. Science, 210(4474), pp. 1094-1098, 1980.

[4] Muraoka, H., Takenaka, A., Tang, Y., Koizumi, H. \& Washitani, I., Flexible Leaf Orientations of Arisaema heterophyllum Maximize Light Capture in a Forest Understorey and Avoid Excess Irradiance at a Deforested Site. Annals of Botany, 82(3), pp. 297-307, 1998.

[5] Brunig, E.F., Tree forms in relation to environmental conditions: an ecological viewpoint. Eds. M.G.R. Cannell \& F.T. Last, Tree Physiology and Yield Improvement, Academic Press: London, pp. 139-156, 1976.

[6] Loomis, R.S., Williams, W.A., \& Hall, A.E., Agricultural productivity. Annual Review of Plant Physiology, 22, pp. 431-468, 1971.

[7] Pearcy, R.W., Muraoka, H. \& Valladares, F., Crown architecture in sun and shade environments: assessing function and trade-offs with a threedimensional simulation model. New Physiologist, 166(3), pp. 791-800, 2005.

[8] Knaack, U., Tillmann, K., Bilow, M. \& Auer, T., Facades: Principles of Construction, BIRKHAUSER: Berlin, pp. 80-82, 2007.

[9] Olgyay, V., Design with climate, bioclimatic approach to architectural regionalism. Van Nostrand Reinhold: New York, 1992.

[10] Takenaka, A., Inui, Y. \& Osawa, A., Measurement of three-dimensional structure of plants with a simple device and estimation of light capture of individual leaves. Functional Ecology, 12(1), pp. 159-165, 1998. 
[11] Kriegh, M. \& Kriegh, J., Growth, Form and Proportion in Nature: Lessons for Human Habitation in off Planet Environments. Proc. of the 33rd Int. Conf. On Environmental Systems (ICES). Warrendale: Pennsylvania, USA, Vancouver, British Columbia, Canada, 2003.

[12] Horn, H.S., Adaptive Geometry of Trees. Princeton University Press: London, 1971.

[13] Niklas, K.J., The Role of Phyllotatic Pattern as a "Developmental Constraint" On the Interception of Light by Leaf Surfaces. Evolution, 42(1), pp. 1-16, 1988.

[14] Mullen, J.L., Weinig, C. \& Hangarter, R.P., Shade avoidance and the regulation of leaf inclination in Arabidopsis. Plant, Cell \& Environment, 29(6), pp. 1099-1106, 2006.

[15] Darwin, C., The Power of Movement in Plants, Murray: London, 1880.

[16] Forseth, I. \& Ehleringer, J.R., Solar tracking response to drought in a desert annual. Oecologia, 44(2), pp. 159-163, 1980.

[17] Mooney, H.A. \& Ehleringer, J.R., The carbon gain benefits of solar tracking in a desert annual. Plant, Cell Environment 1(4), pp. 307-311, 1978.

[18] King, D.A., The Functional Significance of Leaf Angle in Eucalyptus. Australian Journal of Botany, 45(4), pp. 619-639, 1997.

[19] Falster, D.S. \& Westoby, M., Leaf size and angle vary widely across species: what consequences for light interception? New Phytologist, 158(3), pp. 509-525, 2003.

[20] Barradas, V.L., Jones, H.G. \& Clark, J.A., Leaf orientation and distribution in a Phaseolus vulgaris L. crop and their relation to light microclimate. International Journal of Biometeorology, 43(2), pp. 64-70, 1999.

[21] Satter, R.L., Leaf movements and tendril curling. Encyclopedia of Plant Physiology, new series, (7), Physiology of Movements, eds. W. Haupt \& M.E. Feinleib, Springer: Berlin, Heidelberg, New York, pp. 442-484, 1979.

[22] Bar-Cohen, Y., (ed.). Biomimetics: Biologically Inspired Technologies, CRC Press: Boca Raton, 2006.

[23] Alexander, R.M., Exploring Biomechanics: Animals in Motion. Scientific American Library: New York, 1992.

[24] Fitting, H., Harder, R., Schumacher, W. \& Firbas, F., Lehrbuch der Botanik fur Hochschulen. Pscator: Stuttgart, 1950.

[25] Paturi, F.R., Nature, Mother of Invention: The Engineering of Plant Life. Thames and Hudson: London, 1976.

[26] An interview explores the design concept of DP Architects in designing the Esplanade. http://www.geocities.com/shinyeesiek/vikas.htm

[27] Hausladen, G., Saldanha, M. \& Liedl, P., ClimaSkin: Konzepte fur Gebaudehullen, die mit weineger Energie mehr leisten. Callwey: Munich, 2006.

[28] Badarnah, L. \& Knaack, U., Bio-Inspired Ventilating System for Building Envelopes. Proc. of the Int. Conf. of $21^{\text {st }}$ Century: Building Stock Activation, ed. Y. Kitsutaka, TIHEI: Tokyo, pp. 431-438, 2007. 